\title{
Effect of Different Threshing Methods on Seed Quality of Little Millet cv. CO (Samai)
}

\author{
R. Senthil Raj ${ }^{1 *}$, A. Sabir Ahamed ${ }^{1}$, K. Sujatha ${ }^{1}$ and V. Manonmani ${ }^{2}$ \\ ${ }^{I}$ Department of Seed Science and Technology, AC \& RI - Madurai, TNAU, \\ Coimbatore, Tamil Nadu, India \\ ${ }^{2}$ Department of Seed Science and Technology, TNAU, Coimbatore 641 003, \\ Tamil Nadu, India \\ *Corresponding author
}

\section{A B S T R A C T}

Ke y w or d s
Little millet,
Harvesting,
Physiological
quality, Threshing,
Seed quality

\section{Introduction}

Little Millet is one of the important small millet in the tropics (12 per cent of global millet area) and is cultivated over more than 25 countries in Africa (Eastern and Southern) and Asia (from near East and Far East), predominantly as a staple food grain. Whole crop little millet was harvested manually and transported to threshing yard, where it is threshed by a tractor with or without a stone roller was passed over the crop spread uniformly on the floor. It is estimated that harvesting and threshing of crops consume about one third of the total requirement of the production system (Ojha and Devnani, 1987).Harvest and post-harvest operations were the second most energy consuming operations for both rainfed and irrigated crops, since in traditional agriculture, more human power was used for these operations (Chowdegowda et al., 2010). Mahmoud and Buchele (1975) found that, ear axis parallel to cylinder axis orientation suffered the least damage at all moisture content levels tested, followed by ears fed randomly to the cylinder. 
The highest damage was suffered by ears fed with their axis perpendicular to the cylinder. The minimum damage for all orientations was at 20 to 22 per cent moisture content. They found that the corn kernel damage increased with an increase in moisture content and cylinder velocity. Mechanical damage, threshing effectiveness and power required in threshing wheat were measured for different types of cylinders, cylinder speeds and concave clearances. The data indicated that cylinders fitted with rasp-bar found to be less power requirement than other types (Singh and Kumar, 1976). Dhand (1980) modified a commercial paddy thresher with rasp-bar type cylinder for threshing wheat and found that this machine could handle paddy as well as wheat with minor adjustments. Present study was planned to the different threshing methods on seed quality of little millet cv. CO (Samai) 4

\section{Materials and Methods}

The study was conducted with little millet seeds obtained from the Department of millets, Tamil Nadu Agricultural University, Coimbatore formed the base material for this study. The experiment was conducted at the department of seed science and technology, AC\&RI, Madurai to determine the different threshing methods on seed quality. Little millet panicles were harvested manually from the bulk crop raised. The dried panicles of $100 \mathrm{~kg}$ each were threshed by different threshing methods viz...

$\mathrm{T}_{1^{-}}$Manual threshing (beating with pliable stick)

$\mathrm{T}_{2^{-}}$Tractor trampling (55 HP tractor for 15 mins)

$\mathrm{T}_{3^{-}}$Mechanical threshing (using paddy thresher)
This was replicated seven times and the seeds obtained after threshing by different methods were analyzed for following parameters.

\section{Time taken for threshing}

The time taken for threshing the specified quantity of panicles in each threshing method was recorded and expressed in minutes.

\section{Seed recovery}

The cleaned seeds obtained after each threshing method were weighed and the seed recovery per cent was worked out using the following formula:

Seed recovery $(\%)=\frac{\text { Weight of cleaned seed }}{\text { Weight of the panicles }} \times 100$

\section{Mechanical injury}

The seeds obtained by different threshing methods were subjected to fast green mechanical injury test, where 200 seeds taken in a $250 \mathrm{ml}$ beaker and containing $0.25 \%$ fast green solution for 15 seconds then remove the fast green solution and seeds were rinsed with water, damaged seeds appears green and the seed mechanical injury percentage was worked out using the following formula,

Mechanical injury $(\%)=\frac{\text { Number of seeds mechanically damaged }}{\text { Total number of seeds taken }} \times 100$

\section{Germination}

Germination test was carried out in quadruplicate using 100 seeds each in rolled paper towel method (ISTA, 1999) in a germination room maintained at $25 \pm 1{ }^{\circ} \mathrm{C}$ temperature and $96 \pm 2 \%$ relative humidity (RH) with diffused light during the day. On tenth day of germination test, number of normal seedlings was counted and the average was expressed as per cent. 


\section{Root length}

Ten normal seedlings were selected randomly from the germination test and root length was measured from tip of primary root to base of shoot and mean root length was expressed in $\mathrm{cm}$.

\section{Shoot length}

Ten normal seedlings chosen for measurement of root length were used for measurement of shoot length. It was measured from tip of primary leaf to base of shoot and mean shoot length was expressed in $\mathrm{cm}$

\section{Seedling dry matter production}

Ten normal seedlings chosen earlier for measuring shoot and root lengths were used to determine seedling dry weight. The seedlings kept in paper cover and dried under shade for $24 \mathrm{~h}$ and then in a hot air oven at $85 \pm 1^{\circ} \mathrm{C}$ for 24 hours. The average weight was expressed in gram per ten seedlings.

\section{Vigour index}

Seedling vigour index was computed by adopting the following formula as suggested by Abdul-Baki and Anderson (1973) and was expressed in whole number.

Vigour index $=$ Germination percentage $\mathrm{x}$ Total seedling length in centimeter

\section{Statistical analysis}

The data obtained from experiments were analyzed by the ' $F$ ' test for significance by following Completely Randomized Design. Wherever necessary, the percent values were transformed to angular (Arc-sine) values before analysis. The critical differences (CD) were calculated at 5 per cent probability level. The data were tested for statistical significance (Gomez and Gomez, 1984)

\section{Results and Discussion}

Time taken for threshing, Seed recovery, Mechanical injury

Time taken for threshing (min) specified quantity of panicles in each threshing method differed significantly. The highest time in manual beating with pliable stick $(85 \mathrm{~min})$ while, the minimum time was taken in mechanical threshing with paddy thresher with $13 \mathrm{~min}$. (Table 1). Seed recovery was potential of the seeds obtained from different seed threshing methods differed significantly. Among the treatments, the seeds obtained from manual beating with pliable stick registered the highest seed recovery of 67.8 per cent and was followed by mechanical threshing with paddy thresher $(65.2 \%)$ and was the lowest for the seeds recovery from tractor treading $(60.5 \%)$ (Table 1). Mechanical injury (\%) of seeds obtained from different seed threshing methods differed significantly. Among the treatments, tractor treading recorded the highest mechanical injury of 15 per cent and was followed by mechanical threshing with paddy thresher (6 $\%$ ). The lowest mechanical injury was due to manual beating with pliable stick (4\%) (Table 1).

\section{Germination, Root length, Shoot length}

Germination potential of the seeds obtained from different seed threshing methods differed significantly. Among the treatments, the seeds obtained from manual beating with pliable stick registered the highest germination of 81 per cent and was followed by mechanical threshing with paddy thresher $(80 \%)$. The seeds obtained from tractor treading had only 63 per cent germination (Table 1). Among the different treatments, the seeds obtained from manual beating with pliable stick recorded the highest root length of $10.1 \mathrm{~cm}$ followed by mechanical threshing with paddy thresher $(9.8 \mathrm{~cm})$ and the tractor 
treading recorded the lowest root length of 8.7 $\mathrm{cm}$ (Table 1). The seeds obtained from manual beating with pliable stick recorded the highest shoot length of $8.8 \mathrm{~cm}$ and was followed by mechanical threshing with paddy thresher $(8.3 \mathrm{~cm})$. The lowest shoot length of $7.6 \mathrm{~cm}$ was recorded in seeds received from tractor treading (Table 1).

\section{Seedling dry matter production, Vigour index}

Among the different treatments, the seeds obtained from manual beating with pliable stick threshing registered the highest seedling dry matter production of $0.05 \mathrm{~g}$ and the lowest in tractor treading with $0.03 \mathrm{~g}$. The seedling dry matter production registered by mechanical threshing with paddy thresher was 0.04 g. (Table 1). Among the treatments, the seeds obtained from manual beating with pliable stick threshing registered the highest vigour index (1512) followed by mechanical threshing with paddy thresher (1466) and the lowest by tractor treading 1027 (Table 1).

Table.1 Effect of different threshing methods on seed and seedling quality characteristics of little millet cv. CO (Samai) 4

\begin{tabular}{|c|c|c|c|c|c|c|c|c|}
\hline $\begin{array}{c}\text { Threshing } \\
\text { method }\end{array}$ & $\begin{array}{c}\text { Time } \\
\text { taken for } \\
\text { threshing } \\
\text { (min) }\end{array}$ & $\begin{array}{c}\text { Seed } \\
\text { recovery } \\
\text { (\%) }\end{array}$ & $\begin{array}{c}\text { Mechanical } \\
\text { injury (\%) }\end{array}$ & $\begin{array}{c}\text { Germination } \\
\text { (\%) }\end{array}$ & $\begin{array}{c}\text { Root } \\
\text { length } \\
\text { (cm) }\end{array}$ & $\begin{array}{c}\text { Shoot } \\
\text { length } \\
\text { (cm) }\end{array}$ & $\begin{array}{c}\text { Seedling } \\
\text { dry matter } \\
\text { production } \\
\text { (g 10 seedlings -1) }\end{array}$ & $\begin{array}{c}\text { Vigour } \\
\text { index }\end{array}$ \\
\hline $\begin{array}{c}\text { Manual } \\
\text { beating with } \\
\text { pliable stick }\end{array}$ & 85 & $\begin{array}{c}67.8 \\
(54.94)\end{array}$ & $\begin{array}{c}4 \\
(11.53)\end{array}$ & $\begin{array}{c}81 \\
(64.15)\end{array}$ & 10.1 & 8.8 & 0.05 & 1512 \\
$\begin{array}{c}\text { Tractor } \\
\text { treading }\end{array}$ & 15 & $\begin{array}{c}60.5 \\
(50.18)\end{array}$ & $\begin{array}{c}15 \\
(22.78)\end{array}$ & $\begin{array}{c}63 \\
(52.53)\end{array}$ & 8.7 & 7.6 & 0.03 & 1027 \\
\hline $\begin{array}{c}\text { Mechanical } \\
\text { threshing } \\
\text { with paddy } \\
\text { thresher }\end{array}$ & 13 & $\begin{array}{c}65.2 \\
(53.73)\end{array}$ & $\begin{array}{c}6 \\
(14.17)\end{array}$ & $\begin{array}{c}80 \\
(63.43)\end{array}$ & 9.8 & 8.3 & 0.04 & 1466 \\
\hline Mean & $\mathbf{3 7 . 7}$ & $\begin{array}{c}\mathbf{6 4 . 5} \\
\mathbf{( 5 3 . 1 3 )}\end{array}$ & $\begin{array}{c}\mathbf{8 . 3} \\
(\mathbf{1 6 . 4 3 )}\end{array}$ & $\begin{array}{c}\mathbf{7 4 . 7} \\
\mathbf{( 5 9 . 3 4 )}\end{array}$ & $\mathbf{9 . 5 3}$ & $\mathbf{8 . 2}$ & $\mathbf{0 . 0 4}$ & $\mathbf{1 3 3 5}$ \\
\hline SEd & 0.38 & 1.51 & 0.26 & 1.54 & 0.063 & 0.15 & 0.0007 & 45.82 \\
\hline CD (0.05) & $1.08^{* *}$ & $2.21^{* * *}$ & $0.74 * *$ & $2.28^{* *}$ & $0.171^{* *}$ & $0.43^{* * *}$ & $0.0020^{* * *}$ & $127.2^{* * *}$ \\
\hline
\end{tabular}

(Figures in parentheses indicate Arcsine value)

Fig.1 Effect of different threshing methods on seed recovery (\%) and mechanical injury (\%) in little millet cv. CO (Samai) 4

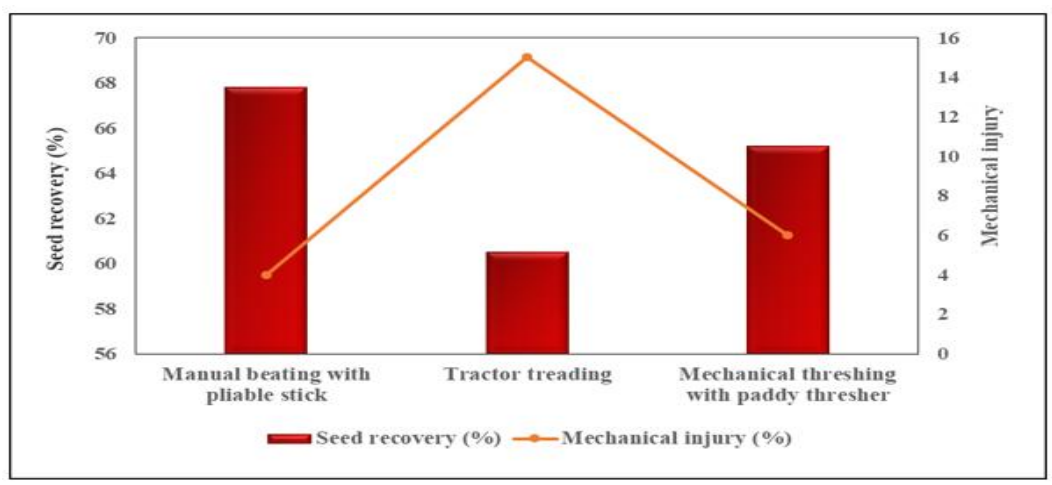


Fig.2 Effect of different threshing methods on germination (\%) and vigour index in little millet cv. CO (Samai) 4

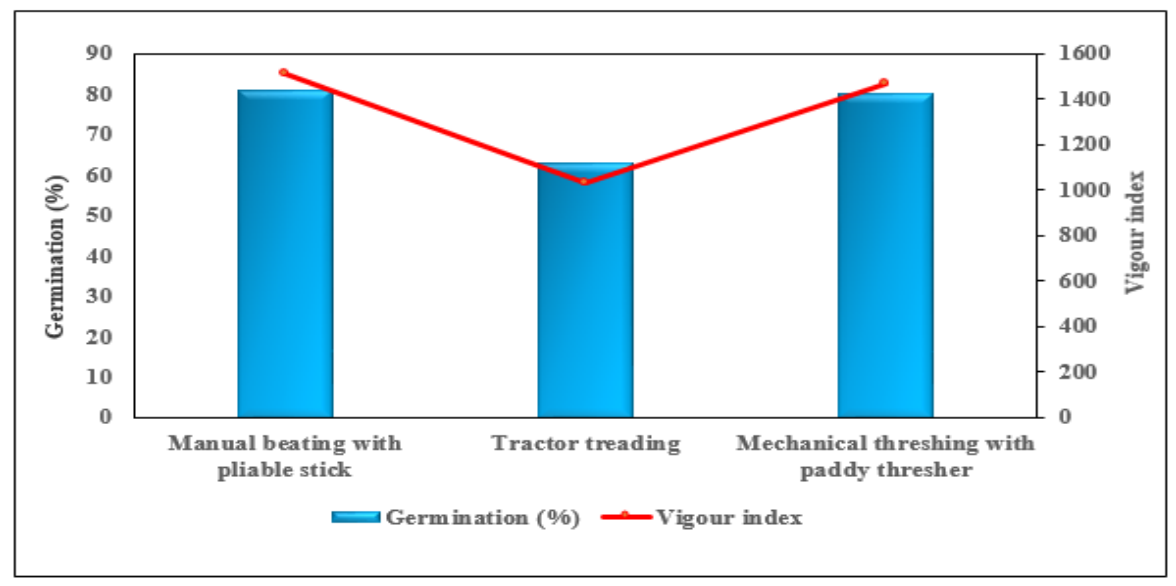

Seed processing is a fundamental component in any planned seed production programme, which aims at improving the seed characteristics (Araujo et al., 2008). Threshing is the removal of grain from harvested plant head or plant part (Kajuna, 2001). This post-harvest processing could be done through traditional manual method or modern mechanical method. However, manual system of threshing cereal failed to meet up with this growing demand of cereals and is labour intensive (Singh and Joshi, 1979). In the present studies, little millet cv. CO (Samai) 4 harvested panicles were put to three methods of threshing viz., manual beating with pliable stick, tractor treading and using paddy thresher. After threshing, the cleaned seeds were tested for germination and vigour index.

Among the threshing methods, the manual beating method recorded the highest seed recovery $(67.8 \%)$, germination $(81 \%)$, seedling growth characters and vigour index (1512) followed by mechanical threshing with paddy thresher with 65.2 per cent seed recovery, 80 per cent germination and (1466) vigour index respectively (Fig. 1). Correspondingly, the mechanical damage in the above two methods was very minimum with 4 and 6 per cent respectively as compared to 15 per cent in tractor treading method. Due to high mechanical damage, the seed germination and seedling vigour also reduced in tractor treading method. However, the time taken by the manual beating method was very high (85 minutes) as compared mechanical threshing with paddy thresher and tractor treading with only 13 and 15 minutes respectively. The increase in germination percentage and maximum seed recovery by beating with pliable stick were also in agreement with Mundhe et al., (2005) and Surve et al., (2015).

Mechanical damage is considered the most common reason for poor seed quality in large seeded legumes. This occurs when seeds are threshed at unsuitable seed moisture content at a high drum speed. Similar trend was also observed in tractor treading and paddy thresher. The extended of mechanical threshing by paddy thresher was very less when compared to tractor treading. This might possibly due to less injury of seeds in threshing with paddy thresher at required moisture content. More mechanical damage might lead to production of more abnormal 
seedlings. This is due to production of more breaks, cracks, bruises and abrasions in seeds which caused internal injury to the embryo and finally resulted in more number of abnormal seedling (Green et al., 1966; Reddy et al., 1995).

Though, the vigour and viability of seeds obtained from hand and mechanical threshing were better than tractor treading, hand threshing may not be economical since it is laborious, more time consuming and low in threshing efficiency. Therefore, it could be concluded that mechanical threshing with paddy thresher is a feasible method to obtain good quality seeds with maximum threshing efficiency for large scale seed production of little millet. This is in close conformity with the findings of Ramanadane and Ponnuswamy (2009) in hybrid rice. Prasanna (2013) also concluded that replacing tractor treading by threshing machines reduced the post-harvest losses and increased the net income (Fig. 2).

In conclusion the threshing is the most critical aspects in post-harvest handling of grain seeds especially with maintenance of quality. The traditional methods of threshing is tedious, time consuming and inefficient. Hence, mechanical threshing is a means to overcome the above problems. To find out the efficient method of threshing in seed crop of little millet $\mathrm{cv}$. CO (Samai) 4, the harvested panicles were subjected to three threshing methods viz., manual beating with pliable stick, tractor treading and using paddy thresher and the resultant seeds were tested for germination and seedling vigour. Among the threshing methods, the manual beating method recorded the highest seed recovery (67.8 \%), germination (81 \%), seedling growth characters and vigour index followed by mechanical threshing with paddy thresher. Due to high mechanical damage, the seed germination and seedling vigour also reduced in tractor treading method. However, the time taken by the manual beating method was very high (85 minutes) as compared mechanical threshing with paddy thresher and tractor treading with only 13 and 15 minutes respectively. Therefore, mechanical threshing with paddy thresher is a feasible method to obtain good quality seeds with maximum threshing efficiency for large scale seed production of little millet.

\section{References}

Araujo, R.F., E.F. Araujo, R.F.Vieira, V. Sofiatti, J.B. Zonta, and L.T. Souza. 2008. Physiological and sanitary quality of mung beans subjected to post-harvest mechanical processing. Revista Brasileira de Armazenamento, 33(1): 43-45.

ChowdeGowda, M., Sreenatha, A., Ramya, H.N. and Jayamala, G.B., 2010. Estimation of Energy Requirement for Finger millet (Eleusine G.) Cultivation in Karnataka (India). International Journal of Applied Agricultural Research, 5(1)1-8.

Dhand, N.K., 1980, Modification of an existing rasp bar paddy thresher for wheat.B. Tech. Project Report, College of Agricultural Engineering, PAU, Ludhiana, India.

Green, D. E., L. E. Cavanah and E. L. Pinnell. 1966. Effect of seed moisture content, field weathering and combine cylinder speed on soybean seed quality. Crop Sci., 6:pp.7-10

Kajuna, S.T.A.R. 2001. MILLET: Postharvest Operations. SokoneUniv. of Agric.,35-39.

Mahmoud, A.R. And Buchele, W.F., 1975, Distribution of shelled corn through put and mechanical damage in a combine cylinder. Trans. of the ASAE 18(2): 448- 452.

Mundhe, A. V. 2005. Effect of moisture content and mechanical processing on 
soybean seed quality. J. Maharashtra Agric. Uni., 30(2): 218-220.

Ojha, T.P And Devnani 1987, status of harvesting machinery in India-a Country report 'Regional work shop on Design and Development of harvesting and Threshing Equipment' IARI, New Delhi, October 4-14.

Prasannakumar and D. B. Naveen kumar. 2012. Performance evaluation of threshing of finger millet by mechanical method. Intl J. Agric. Eng., 5(2): 186191.

Ramanadane, T. and A.S. Ponnuswamy. 2009. Standardization of threshing and drying methods in hybrid rice (Oryza sativa L.) seed production, Agric. J. of Agric. Sci., 7(5).
Reddy, D. M. V., A. B. Gowda and K. M. P. Murthy. 1995. Effect of seasons and threshing methods on seed quality and longevity in soybean. Seed Res., 23: 8083.

Singh, B. And Kumar, A., 1976, Effect of cylinder type on threshing effectiveness and damage of wheat. J. Agril. Egg. 13(3): 124-129.

Singh, K. and H.C. Joshi, 1979. Axial Flow Thresher. Appropriate Techn. Newsletter, U.P. India, 2(4): 5-6.

Surve, U. S., P. C. Patil and K. C. Gagre. 2015. Response of soybean varieties to different threshing methods and storage potential. Intl. J. of Tropic. Agric., 33 (2): $1237-1240$

\section{How to cite this article:}

Senthil Raj, R., A. Sabir Ahamed, K. Sujatha and Manonmani, V. 2021. Effect of Different Threshing Methods on Seed Quality of Little Millet cv. CO (Samai). Int.J.Curr.Microbiol.App.Sci. 10(02): 1027-1033. doi: https://doi.org/10.20546/ijcmas.2021.1002.121 